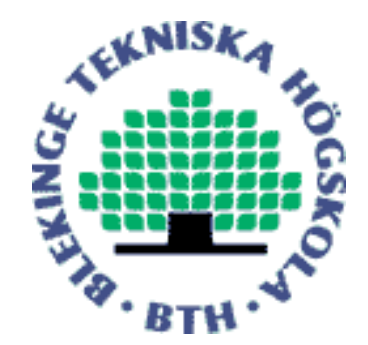

Copyright @ 2012 IEEE.

Citation for the published paper:

Title:

Quality Requirements in Industrial Practice - An Extended Interview Study at Eleven Companies

Author:

Richard Berntsson Svensson, Tony Gorschek, Björn Regnell, Richard Torkar, Ali Shahrokni, Robert Feldt

Journal:

IEEE Transactions on Software Engineering

Year:

2012

Vol:

38

Issue:

4

Pagination:

923-935

URL/DOI to the paper:

10.1109/TSE.2011.47

This material is posted here with permission of the IEEE. Such permission of the IEEE does not in any way imply IEEE endorsement of any of BTH's products or services Internal or personal use of this material is permitted. However, permission to reprint/republish this material for advertising or promotional purposes or for creating new collective works for resale or redistribution must be obtained from the IEEE by sending a blank email message to pubs-permissions@ieee.org.

By choosing to view this document, you agree to all provisions of the copyright laws protecting it. 


\title{
Quality Requirements in Industrial Practice - an extended interview study at eleven companies
}

\author{
Richard Berntsson Svensson, Tony Gorschek, Björn Regnell, \\ Richard Torkar, Ali Shahrokni, and Robert Feldt
}

\begin{abstract}
In order to create a successful software product and assure its quality, it is not enough to fulfill the functional requirements, it is also crucial to find the right balance among competing quality requirements (QR). An extended, previously piloted, interview study was performed to identify specific challenges associated with the selection, trade-off, and management of QR in industrial practice. Data was collected through semi-structured interviews with eleven product managers and eleven project leaders from eleven software companies. The contribution of this study is fourfold: First, it compares how QR are handled in two cases, companies working in business-to-business markets, and companies that are working in business-toconsumer markets. These two are also compared in terms of impact on the handling of QR. Second, it compares the perceptions and priorities of QR by product and project management respectively. Third, it includes an examination of the interdependencies among quality requirements perceived as most important by the practitioners. Fourth, it characterizes the selection and management of QR in down-stream development activities.
\end{abstract}

Index Terms-Management; Process; Requirements/Specifications

\section{INTRODUCTION}

A $\mathrm{S}$ the role of software increases and becomes a substantial part of industrial and consumer products, the complexity also escalates, making the process area of requirements engineering (RE) central for success [28]. The characteristics of a product are determined by functionality, but also by the non-functional or quality aspects, a.k.a. quality requirements $(\mathrm{QR})$, such as performance and usability [9].

To create a successful product and assure quality, it is not enough to fulfill the functional requirements. For example, even if the product works, it may be difficult to use, or too costly to maintain [12]. The importance of having a handle on QR can be seen as obvious; however, when it comes to customer satisfaction, end-users are often dissatisfied with software quality [24]. Therefore, QR play a critical role in software product development, and not dealing with QR may lead to more expensive

- R. Berntsson Svensson is with the Department of Computer Science, Lund University, PO Box 118, 22100 Lund, Sweden. E-mail: rich-

ard.berntsson_svensson@cs.lth.se

- T. Gorschek is with the School of Computing, Blekinge Institute of Technology,37179 Karlskrona, Sweden. E-mail: tony.gorschek@bth.se

- B. Regnell is with the Department of Computer Science, Lund University, PO Box 118, 22100 Lund, Sweden.E-mail: bjorn.regnell@cs.lth.se

- $R$. Torkar is with the School of Computing, Blekinge Institute of Technology, 37179 Karlskrona, Sweden. E-mail: richard.torkar@bth.se.

- A. Shahrokni is with the Software Engineering and Technology, Chalmers University of Technology, SE-41296 Göteborg, Sweden. E-mail: nimli@chalmers.se

- R. Feldt is with the Software Engineering and Technology, Chalmers University of Technology, SE-41296 Göteborg, Sweden. E-mail: robert.feldt@bth.se

Manuscript received (insert date of submission if desired). Please note that all acknowledgments should be placed at the end of the paper, before the bibliography. software products and increased time-to-market [11]. The ability to develop a software product that meets customers' requirements, and offers high value to both the development company and the customer, increases the likelihood of market success substantially, thus QR play a central role and can be seen as a key competitive advantage [2], [4].

However, despite their importance, QR are often poorly understood, generally stated informally in a nonquantifiable manner, often contradicting, and difficult to validate [9], [22]. This is further aggravated in marketdriven development, where the situation is even more complex [3], due to the large number of requirements stemming from multiple internal and external sources, and the continuous flow into the development organization [16], [18]. The challenges associated with QR have been addressed in part by other studies, see e.g. [25], [26], and [32]. However, none of these have primarily focused on $\mathrm{QR}$.

This paper presents the results of an empirical study that includes data collected through in-depth interviews with twenty-two practitioners from eleven different companies in Sweden of which six are multinational. After ten interviews from five companies, a short paper [6] was presented at an international workshop. The study focuses on the elicitation, analysis and negotiation, management, and general handling of QR in industry. This exploratory study can be seen as a study of state-of-practice in industry, but also an investigation as to what extent state-of-the-art in research, in terms of methods and tools, has penetrated industry practice.

The study incorporates two main perspectives with re- 
gards to QR [15], through the study of companies with two distinctly different types of customers. Six of the companies mainly develop and sell products to other companies. For example, a company developing industry robots does not sell to traditional consumers, but rather to other companies that use the robots in their product development. These companies are denoted business-tobusiness (B2B) [39]. The second type of companies in the study develops products for the consumer market, for example mobile phones or laptops. These companies are denoted business-to-consumer (B2C) [39] in the paper. The comparison between the two company categories $\mathrm{B} 2 \mathrm{~B}$ and $\mathrm{B} 2 \mathrm{C}$ is the main focus of the paper; however, in each company we elicited information about $\mathrm{QR}$ handling from two roles central to decision making in relation to QR. The overall product responsibility is held by product managers (PM), responsible for the overall product and the selection and long-term planning of the product evolution and offering. The second role studied was that of the project perspective. Project leaders (PL) are responsible for managing and prioritizing within the realization phases. The choice to study both perspectives within each company was motivated by the intention of improving coverage and the further possibility to compare the views to identify possible conflicts [17], [36].

The remainder of this paper is organized as follows. In Section 2, the background and related work are presented. The research methodology is described in Section 3, and Section 4 presents the results and relates the findings to previous studies. Section 5 gives a summary of the main conclusions.

\section{BACKGROUND AND RELATED WORK}

There are several surveys in literature that include $Q R$ related challenges.

Laubars et al. published their field study on requirements modeling [32]. Their study included both customer-specific and market-driven projects. The challenges found by Laubars et al. include e.g. vaguely stated requirements, requirements misunderstandings, changing requirements, and difficulties with prioritization of requirements [32]. Moreover, two challenges related to performance requirements were identified, specification (rational not always obvious) and associating performance requirements with dataflow specifications. Later, a study on requirements engineering challenges in small and medium sized enterprises was presented by Kamsties et al. [25]. Similar to Laubars et al. [32], customer-specific and market-driven projects were represented. Kamsties et al. [25] agree to some extent with Laubars et al. [32] and identified unclear and incomplete requirements as challenges. Other identified challenges are: specification of graphical users interfaces and lack of traceability among requirements. Moreover, Kamsties et al. [25] found that requirements are too vague to test. A study that solely focuses on market-driven software development challenges was published by Karlsson et al. [26]. Challenges related to quality requirements were identified by Karlsson et al. [26], where the main problem was interdepend- encies related to $\mathrm{QR}$. This problem is not only related to identifying existing interdependencies, but also to what extent QR affect each other and how to deal with it. Moreover, supporting release planning of $Q R$ caused problems for the companies. Berntsson Svensson et al. conducted a field study to discover and describe how $\mathrm{QR}$ are handled in industry [6]. The findings highlight three important challenges, how to get $\mathrm{QR}$ into the projects when functional requirements are prioritized, how to know when the quality level is good enough, and how to achieve testable QR.

Finally, there are a number of studies that are not focusing on challenges, but focus on requirements interdependencies [7], [9], [10], and classification and measurement of QR [22], [34]. For example, Carlshamre et al. identified a set of interdependency types that are present in industry [7], while Olsson et al. concluded that methods need to handle the diversity of QR [34].

The focus of the above mentioned studies, with the exception of Berntsson Svensson et al. [6], has not been primarily on QR, but QR-related findings emerged as parts of the results. This paper presents a study with the primary focus on $Q R$ and how they are managed in the RE process. Even though Berntsson Svensson et al. [6] solely focused on $Q R$, only five companies were included in the study with a primary focus on PM and PL perspectives. In this study we have extended the data to eleven companies, and, in addition, included challenges related to cost estimation of $\mathrm{QR}$ as well as the perspective of comparing $\mathrm{B} 2 \mathrm{~B}$ and $\mathrm{B} 2 \mathrm{C}$ in the analysis, which presents new data from all eleven cases.

\section{Research Methodology}

The investigation presented in this paper was carried out using a qualitative research approach, namely in-depth semi-structured interviews [37]. Qualitative research aims to investigate and understand phenomena within its real life context [37]. A qualitative research approach is useful when the purpose is to explore an area of interest, and when the aim is to improve the understanding of phenomena [37], [38]. The purpose of this study is to gain indepth understanding of $\mathrm{QR}$ within market-driven embedded systems companies. Due to the potential richness and diversity of data that could be collected, semistructured interviews would best meet the objectives of this study. Semi-structured interviews help to ensure common information on pre-determined areas is collected, but allow the interviewer to probe deeper where required.

We choose interviews over doing a large survey as the concept of $\mathrm{QR}$ are named and treated very differently in industry, what might be called a quality requirement in one place is simply adherence to product limitations in another [1]. For this reason it was important to have a presence when eliciting the data making it possible to elaborate on what we were looking for and compensate for these differences in culture and naming. Several times 
we had to put five to ten minutes of explanation ${ }^{1}$ into what we were investigating before the interview subject understood and we could proceed. In addition, the interviewer had the chance to validate the questions with the interviewee lessening changes of misunderstandings. That is, the interviewer went back to the interviewee to validate the interviewers interpretation of the results to minimize misinterpretations and validate the results. The research questions in Table 1 provided a focus for the empirical investigation.

TABLE 1

RESEARCH QUESTIONS

\begin{tabular}{l} 
Research Questions (QR \\
Quality Requirements) \\
\hline RQ1: What QR are considered \\
most important, and are there \\
any distinguishably characteris- \\
tics in relation to customer type \\
(B2B vs. B2C)? \\
RQ2: What interdependencies \\
between QR are present in the \\
companies? \\
RQ2.1: What interdepend- \\
encies are deemed most \\
important, and how does \\
this compare to previous \\
studies? \\
RQ2.2: To what extent are \\
interdependencies elicited, \\
analyzed and documented?
\end{tabular}

RQ3: How are cost estimations of QR performed, and what is the accuracy of these cost estimates?

RQ4: To what extent are QR dismissed from projects after project initiation?

RQ4.1: If QR are dismissed, is any consequence analysis performed pre- or post dismissal?

RQ4.2: Are QR specified in a measurable (quantifiable) manner?

Berntsson Svensson and Aurum [5] discovered that there are differences in which factors are important for project/product success across industries. Therefore, it is important to investigate what quality aspects are considered most important across industries developing products for different customers (RQ1). In addition, Karlsson et al. discovered that it is possible to manage functional dependencies; however, a major problem is to deal with

\footnotetext{
${ }^{1}$ http: / / serg.cs.lth.se/research/experiment_packages / quality_require ments
}

dynamic interdependencies, i.e. quality requirements, which influence a larger part of the functionality or other quality requirements of the system [26]. Therefore, it is important to understand interdependencies related to quality requirements (RQ2). Software cost estimates are the basis for project planning, bidding, and budgeting and are critical for project success [19]. In addition, Berntsson Svensson et al. [6] found that poor cost estimation is one main reason for QR being dismissed after project initiation, therefore, it is important to understand how cost estimations of $\mathrm{QR}$ are performed in industry (RQ3). Kamsties et al. found that requirements are often too vague to test [25], therefore, it is important to investigate if $\mathrm{QR}$ are quantified in industry (RQ4). Also, dismissal of QR from projects may have an impact on the predicted return of investment, as well as the cost for the customers (RQ4).

\subsection{Research Design and Data Collection}

The investigation can be divided into three phases:

Planning/Selection: The sampling strategy used was a combination of maximum variation sampling [35] and convenience sampling [35] within our industrial collaboration network. The researchers contacted a "gate-keeper" at each company who identified two subjects (one PM and one PL) that he/she thought were the most suitable and representative of the company to participate in this study. That is, the researchers did not influence the selection of subjects, nor did the researchers have any personal relationship to the subjects. Twenty-two participants at eleven software development companies participated. From each company, one product manager (PM) and one project leader (PL) from the same project were interviewed, resulting in twenty-two data points. The research instrument ${ }^{2}$ used in this study, and in [6], was designed with respect to the different areas of interest and inspiration from [26].

All eleven companies develop embedded systems using a market-driven software development approach. The companies themselves vary in respect to size, type of products, type of customers, and application domain, a characterization (following the guidelines of [20]) can be see in Table 2 (more details are not revealed for confidentiality reasons) following the recommendations of [21]. The companies are divided into two main categories based on type of customers: (1) business-to-business [39] companies (B2B), for example, Company E develops control systems for other industry partners, and (2) businessto-consumer [39] companies (B2C) for example, Company $\mathrm{C}$ develops products within the telecom domain for endusers.

http:/ / serg.cs.lth.se/research/experiment_packages / quality_requireme nts 
TABLE 2

COMPANY CHARACTERISTICS

\begin{tabular}{|c|c|c|c|c|c|c|}
\hline & Type of customer & \# Employees & Domain & Development process & $\begin{array}{l}\text { \# of Reqs in a } \\
\text { typical project }\end{array}$ & $\begin{array}{l}\% \text { of } Q R \text { in a } \\
\text { typical project }\end{array}$ \\
\hline A & $\mathrm{B} 2 \mathrm{~B}$ & $\sim 100$ & Control systems & Incremental development & $>1000$ & $\sim 10 \%$ \\
\hline B & $\mathrm{B} 2 \mathrm{~B}$ & $\sim 3000$ & Telecom & Plan-driven & $\sim 7000$ & $\sim 10 \%$ \\
\hline $\mathrm{C}$ & $\mathrm{B} 2 \mathrm{C}$ & $>5000$ & Telecom & Plan-driven & $>20000$ & Unknown \\
\hline $\mathrm{D}$ & $\mathrm{B} 2 \mathrm{C}$ & 325 & Telecom & Agile - Scrum & $\sim 100$ features & $\sim 10 \%$ \\
\hline $\mathrm{E}$ & $\mathrm{B} 2 \mathrm{~B}$ & 65 & Control systems & Waterfall - Iterative & Differs & Differs \\
\hline $\mathrm{F}$ & $\mathrm{B} 2 \mathrm{C}$ & $\sim 700$ & Surveillance & Iterative & $\sim 250$ & $\sim 15 \%$ \\
\hline G & $\mathrm{B} 2 \mathrm{C}$ & $\sim 100$ & Consumer electronics & Plan-driven & $\sim 300$ & $\sim 5 \%$ \\
\hline $\mathrm{H}$ & B2B & $\sim 700$ & Telecom & Agile - Scrum variant & $\sim 200$ & $20 \%$ \\
\hline I & $\mathrm{B} 2 \mathrm{~B}$ & $\sim 50$ & Security & Waterfall and Agile - Scrum & $\sim 100$ & $\sim 15 \%$ \\
\hline $\mathrm{J}$ & $\mathrm{B} 2 \mathrm{~B}$ & $\sim 90$ & Control systems & Plan-driven & $\sim 100$ & $\sim 10 \%$ \\
\hline K & $\mathrm{B} 2 \mathrm{C}$ & 280 & Telecom & Waterfall - iterative & $\sim 1000$ & $\sim 5 \%$ \\
\hline
\end{tabular}

Data collection: The study used a semi-structured interview strategy [37]. One interviewee and one interviewer attended all interviews. During the interviews, the purpose of the study and a general explanation of QR (see footnote two) were presented to the interviewee. Then, questions about the different areas of interests in relation to $\mathrm{QR}$ were discussed in detail. For all interviews, varying in length from 40 to 90 minutes, we took records in the form of written extensive notes in order to facilitate and improve the analysis process.

Analysis: The content analysis [37] involved marking and discussing interesting sections in the recorded notes. The first two authors examined the categories, first individually, and then together in a workshop setting. The category analysis included examination of the content from different perspectives and a search for explicitly stated or concealed pros and cons in relation to how QR are handled in industry. For all statistical tests on the quantitative data given by respondents, a non-parametric Wilcoxon rank sum test [40] with significance tested at the 0.05 level (unless otherwise stated) was performed. This was used as a method to judge between which sets of data there is any discernable difference and thus reduce the number of such possible differences that would otherwise be implied. The raw anonymized data (individual match encoding and ordering) used for the Wilcoxon rank sum tests are available upon request. The results from the analysis and significance levels are found in Section 4.

\subsection{Validity}

In this section, threats to validity in relation to the research design and data collection are discussed. We consider the four perspectives of validity and threats as presented in Wohlin et al. [40].

Construct validity: The construct validity is concerned with the relation between theories behind the research and the observations. The variables in our research are measured through interviews, including open-ended questions where the participants are asked to express their own opinions.

By collecting data from a wide range of sources on the topic, mono-operation bias [40] was avoided. The potential problem of evaluation apprehension [40] was alleviated by the guarantee of anonymity as to all information divulged during the interviews, and the answers was only to be used by the researcher, i.e. not be showed or used by any other participants, companies, or researcher. Another validity threat lies in the question that asked interviewees to rank and include additional factors if the list provided to them was inadequate. Interviewees may have thought that it was easier to rank the provided factors than propose new factors, i.e. some interdependency types may be missing. The quantitative data given by respondents is subjective since it is not based on any objective measurements; there might be differences in how the questions were interpreted that renders the comparisons between $\mathrm{QR}$ invalid regardless of the statistical tests employed.

Conclusion validity: Threats to conclusion validity arise from the ability to draw accurate conclusions. The interviews were conducted at different companies and each interview was done in one work session. Thus, answers were not influenced by internal discussions. To ensure that the interview instrument, including the posed questions, are of high quality to obtain highly reliable measures, several pilot studies were conducted, to avoid poor question and poor layout, prior to conducting the interviews.

Internal validity: These threats are related to issues that may affect the causal relationship between treatment and outcome. Threats to internal validity include instrumentation, maturation and selection threats. The potential problem of instrumentation threats was alleviated by developing the research instrument with close reference to literature relating to quality requirements, influenced by previously validated interview instrument [26], and a previously piloted interview study [6]. Moreover, keeping the interview session to 90 minutes, which was possible by collecting background information before the inter- 
view session started, alleviates maturation threats. Threat to selection bias is always present when study subjects are not fully randomly sampled. However, given that 11 different companies from different industrial networks and geographical locations are included, and interviewees were selected based on their roles by a "gate-keeper" at the companies, this threat has limited effect.

External validity: The external validity is concerned with the ability to generalize the results, i.e. in this case the applicability of the findings beyond the included companies. Qualitative studies rarely attempt to generalize beyond the actual setting since it is more concerned with characterizing, explaining and understanding the phenomena under study. The nature of qualitative designs also makes it impossible to replicate since identical circumstances cannot be recreated. However, the development of a theory can help in understanding other cases and situations. The fact that more than one participant and company acknowledge several of the discovered challenges increases the possibility of transferring the results to other situations. The large number of companies and contexts also contributes to generalizability. To avoid the interaction of selection and treatment, interviewees were selected according to their roles within the company by a "gate-keeper", hence the researchers did not select the subjects themselves. Moreover, companies were selected from different geographical locations.

\section{Results and Analysis}

The following four sub-sections present and discuss one research question each, corresponding to the research questions in Table 1.

\subsection{Important Quality Aspects (RQ1)}

In analyzing Research Question 1 (RQ1), this section examines the most important quality aspects, as illustrated in Figure 1 (note that Figure 1 only visualizes the ranking of QR and is not intended to visually compare B2B and B2C). In Figure 1 we can see the top ranked quality aspects that received at least 10 ranking points by the practitioners, i.e. any quality aspect that received less than 10 points is not displayed in Figure 1.

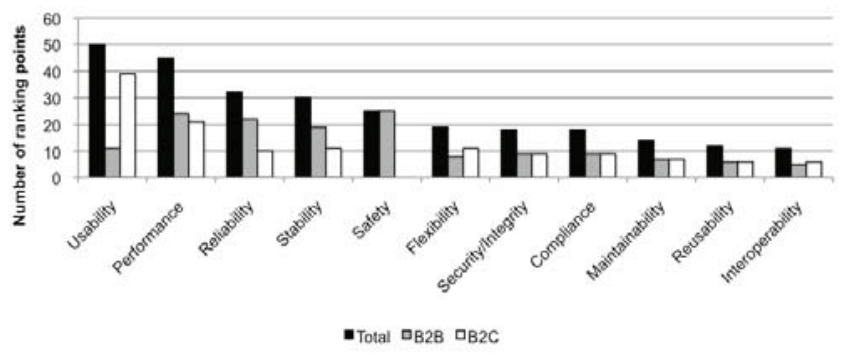

Fig 1. Importance of quality aspects

Based on Lauesen's comparison of ISO9126 and McCall quality factors [29], we identified 23 different types of QR. We asked the interviewees to rank the top five most important aspects for their products based on their expertise and their own definition of the quality aspect (our approach was not to impose preconceived definitions but to try to understand existing industrial practice and practitioners' own interpretations of QR). The interviewees gave five points to the most important, four points to the second most important and so on.

Looking at Figure 1, we see that usability (with 50 ranking points) is the highest prioritized quality aspect among our case organizations. In terms of importance, usability is followed by performance requirements (45 points), reliability (32 points), and stability (30 points). Performing the Wilcoxon rank sum test on the vectors of ranks gives statistically significant p-values of 0.05 for usability from stability and for performance from flexibility and down. However, there is no significant difference between the top ranked aspects of reliability, performance and usability.

Several interviewees explained that an unusable product will never sell. The importance of usability was further explained by one interviewee, "usability is the main competitive advantage, and usability aspects influence the architecture as early decisions". One reason for the prioritization of performance, as explained by several interviewees, is that "performance requirements are always important since the software developed always act as one sub-system in a larger system".

The importance of usability and performance are inline with the findings in Berntsson Svensson et al. [6]. The reason why reliability was ranked as the third most important quality aspects was explained by one interviewee: "the ability to function in extreme environment and to provide long term value is of major importance for our customer". The importance of reliability is confirmed in the study by Johansson et al. [23].

Stability was viewed as important because the customers never accept an unstable product according to one interviewee. Another interviewee explained the importance of having a product that does not have any defects visible to the customer. However, Leung found that the two most important types of QR are availability and accuracy [31], which is not inline with the result in this study. In addition, Leung found that performance requirements (time behavior) are only considered the fifth most important quality aspect. The difference between the studies may be explained by the focus, i.e. we focused on B2B and B2C in a market-driven developing context, while Leung focused on intranet applications [31].

Apart from prioritizing performance requirements as the second most important QR, B2B and B2C prioritized different quality aspects. B2B companies ranked safety (25 points), performance (24 points), and reliability (22 points) as the three most important quality aspects, while B2C ranked usability (39 points), performance (21 points), and stability (11 points) as the most important ones.

A Wilcoxon rank sum test showed a p-value of 0.01 , showing that safety is more important to B2B than B2C. The importance of safety was explained by several interviewees, "because we do not sell our products to consumers, instead we sell to other industry partners". One interviewee expanded the view by stating that it is important to make sure that no humans, material, or the environment are harmed. 
TABLE 3

EXISTING INTERDEPENDENCY TYPES

\begin{tabular}{|c|c|c|c|c|c|c|c|c|}
\hline & \multicolumn{4}{|c|}{ Existing interdependency types } & \multicolumn{4}{|c|}{ Most important types to identify } \\
\hline & \multicolumn{2}{|c|}{ QR to $Q R$} & \multicolumn{2}{|c|}{ QR to FR } & \multicolumn{2}{|c|}{ QR to $Q R$} & \multicolumn{2}{|c|}{ QR to FR } \\
\hline & $P M$ & $P L$ & $P M$ & $P L$ & $P M$ & $P L$ & $P M$ & $P L$ \\
\hline \multicolumn{9}{|c|}{ Business-to-business companies (B2B) } \\
\hline AND & $\mathrm{B}, \mathrm{H}$ & $\mathrm{H}$ & $\mathrm{A}, \mathrm{B}, \mathrm{H}$ & $\mathrm{H}$ & $\mathrm{H}$ & & & \\
\hline OR & $\mathrm{B}, \mathrm{E}, \mathrm{H}$ & $\mathrm{B}, \mathrm{H}$ & $\mathrm{B}, \mathrm{E}$ & $\mathrm{B}, \mathrm{H}$ & $\mathrm{E}$ & & $\mathrm{E}$ & \\
\hline TEMPORAL & $\mathrm{B}, \mathrm{H}$ & $\mathrm{B}, \mathrm{H}$ & $\mathrm{A}, \mathrm{B}, \mathrm{H}, \mathrm{J}$ & $\mathrm{B}, \mathrm{E}, \mathrm{H}, \mathrm{J}$ & & $\mathrm{H}$ & $\mathrm{H}, \mathrm{J}$ & $\mathrm{E}, \mathrm{H}, \mathrm{J}$ \\
\hline REQUIRES & $\mathrm{A}, \mathrm{B}, \mathrm{H}$ & B, E, H & $\mathrm{A}, \mathrm{B}, \mathrm{H}$ & $\mathrm{B}, \mathrm{H}$ & & $\mathrm{B}, \mathrm{E}$ & & B \\
\hline CVALUE & $\mathrm{A}, \mathrm{B}$ & $\mathrm{B}, \mathrm{H}$ & $\mathrm{A}, \mathrm{B}, \mathrm{H}$ & $\mathrm{B}, \mathrm{H}$ & & & & \\
\hline ICOST & $\mathrm{A}, \mathrm{B}, \mathrm{H}$ & $\mathrm{B}, \mathrm{H}$ & $\mathrm{A}, \mathrm{B}, \mathrm{H}$ & $\mathrm{B}, \mathrm{H}$ & A, B & & A, B & \\
\hline \multicolumn{9}{|c|}{ Business-to-consumer companies (B2C) } \\
\hline AND & $\mathrm{C}, \mathrm{F}, \mathrm{G}$ & $\mathrm{C}, \mathrm{F}, \mathrm{K}$ & $\mathrm{C}, \mathrm{G}, \mathrm{K}$ & $\mathrm{C}, \mathrm{D}, \mathrm{F}, \mathrm{G}$ & & & & \\
\hline OR & C, D & $\mathrm{C}, \mathrm{D}, \mathrm{F}, \mathrm{K}$ & $\mathrm{D}$ & $\mathrm{D}, \mathrm{F}$ & & $\mathrm{F}$ & & $\mathrm{F}$ \\
\hline TEMPORAL & & $\mathrm{F}, \mathrm{K}$ & $\mathrm{C}, \mathrm{D}, \mathrm{K}$ & $\mathrm{D}, \mathrm{F}, \mathrm{G}, \mathrm{K}$ & & & & \\
\hline REQUIRES & $\mathrm{C}, \mathrm{K}$ & $\mathrm{C}, \mathrm{D}, \mathrm{F}, \mathrm{G}, \mathrm{K}$ & $\mathrm{C}, \mathrm{D}, \mathrm{F}, \mathrm{G}$ & $\mathrm{C}, \mathrm{D}, \mathrm{F}, \mathrm{G}, \mathrm{K}$ & $\mathrm{C}$ & $\mathrm{D}, \mathrm{G}, \mathrm{K}$ & C, D & $\mathrm{D}, \mathrm{G}, \mathrm{K}$ \\
\hline CVALUE & $\mathrm{C}, \mathrm{F}, \mathrm{G}, \mathrm{K}$ & $\mathrm{C}, \mathrm{D}, \mathrm{F}, \mathrm{G}, \mathrm{K}$ & $\mathrm{C}, \mathrm{D}, \mathrm{F}, \mathrm{G}$ & $\mathrm{C}, \mathrm{D}, \mathrm{F}, \mathrm{G}$ & F, G, K & $\mathrm{C}$ & $\mathrm{F}, \mathrm{G}, \mathrm{K}$ & $\mathrm{C}$ \\
\hline ICOST & $\mathrm{C}, \mathrm{D}, \mathrm{K}$ & $\mathrm{C}, \mathrm{D}, \mathrm{F}, \mathrm{G}, \mathrm{K}$ & C, D & $\mathrm{C}, \mathrm{D}, \mathrm{F}, \mathrm{G}$ & $\mathrm{D}$ & & & \\
\hline
\end{tabular}

One reason for the prioritization of usability for consumer products is, "if the product is not usable we will not sell any products".

B2B companies uniquely identified safety and accuracy as important quality aspects. On the other hand, B2C uniquely identified portability. The difference in priority between B2B and B2C may not be a surprise as different customers are targeted. However the insight of $\mathrm{B} 2 \mathrm{~B}$ and B2C having different priorities is an important insight for e.g. researchers, as it enables focus on certain quality aspects in research depending on company type.

\subsection{Interdependencies (RQ2)}

Based on interviews with requirements engineers at two companies and a proposal, Carlshamre et al. identified a set of six different interdependency types that are present in industry [7]: (1) $\mathrm{R}_{1} A N D \mathrm{R}_{2}: \mathrm{R}_{1}$ requires $\mathrm{R}_{2}$ to function, and $R_{2}$ requires $R_{1}$ to function, (2) $R_{1}$ REQUIRES $\mathrm{R}_{2}: \mathrm{R}_{1}$ requires $R_{2}$ to function, but not vice versa, (3) $R_{1} T E M-$ PORAL $\mathrm{R}_{2}$ : Either $\mathrm{R}_{1}$ has to be implemented before $\mathrm{R}_{2}$ or vice versa, (4) $R_{1} C V A L U E R_{2}: R_{1}$ affects the value of $R_{2}$ for a customer, (5) $\mathrm{R}_{1}$ ICOST $\mathrm{R}_{2}: \mathrm{R}_{1}$ affects the cost of implementing $R_{2}$, and (6) $R_{1}$ OR $R_{2}$ : Only one of $\left\{R_{1}, R_{2}\right\}$ needs to be implemented.

The interviewees had the option of adding additional types of interdependencies, which resulted in one new type discovered during the interviews. The new interdependency type, as explained by the interviewee, is that only one of the requirements can be implemented in this project due to time restrictions (mainly including functional requirements (FR) instead of QR). We call this new interdependency type $R_{1}$ TXOR $R_{2}$, meaning $R_{1}$ for timerelated exclusive or $R_{2}$.
All of the other six predefined interdependency types were used by the interviewees to characterize perceived interdependencies, both among different QR, and interdependencies between QR and FR, as illustrated in Table 3. However, Company I did not recognize/identify any of the interdependency types neither among $\mathrm{QR}$, nor between QR and FR, while Company J did not recognize any of the types among QR.

In general, the most common interdependency types identified among QR were REQUIRES, CVALUE and ICOST (13 of 22, as illustrated in Table 4, which shows a summary view of the frequency of occurrence of the various interdependency types), while the least frequently used one was TEMPORAL (6 of 22). When the preferences were analyzed based on company type the findings show a difference of opinion.

B2B viewed REQUIRES (6 of 12) as the most common type, while B2C viewed CVALUE (9 of 10) as the most common one. When examining the most frequent identified interdependency types between QR and FR, TEMPORAL (15 of 22) was considered most common, while $O R$ (7 of 22) was considered the least frequent one.

However, comparing company types, the findings show a difference. For B2B TEMPORAL (8 of 12) was viewed as the most common type, while $A N D$ and $O R$ (4 of 12) were considered least frequent. On the other hand, for B2C REQUIRES (9 of 10) was considered most common, and $O R$ (3 of 10) was viewed as least frequent by B2C. 
TABLE 4

FREQUENCY OF OCCURRENCE OF INTERDEPENDENCY TYPES

\begin{tabular}{llllll}
\hline AND & OR & TEM- & RE- & CVALUE & ICOST \\
& & PORAL & QUIRES & & \\
\hline
\end{tabular}

\begin{tabular}{|c|c|c|c|c|c|c|}
\hline \multicolumn{7}{|c|}{ Existing interdependency types } \\
\hline \multicolumn{7}{|c|}{ QR to $Q R$} \\
\hline Total & 9 & 11 & 6 & 13 & 13 & 13 \\
\hline B2B & 3 & 5 & 4 & 6 & 4 & 5 \\
\hline $\mathrm{B} 2 \mathrm{C}$ & 6 & 6 & 2 & 7 & 9 & 8 \\
\hline \multicolumn{7}{|c|}{ QR to FR } \\
\hline Total & 11 & 7 & 15 & 14 & 13 & 11 \\
\hline B2B & 4 & 4 & 8 & 5 & 5 & 5 \\
\hline $\mathrm{B} 2 \mathrm{C}$ & 7 & 3 & 7 & 9 & 8 & 6 \\
\hline \multicolumn{7}{|c|}{ Most important types to identify } \\
\hline \multicolumn{7}{|c|}{$Q R$ to $Q R$} \\
\hline Total & 1 & 2 & 1 & 6 & 4 & 3 \\
\hline B2B & 1 & 1 & 1 & 2 & 0 & 2 \\
\hline B2C & 0 & 1 & 0 & 4 & 4 & 1 \\
\hline \multicolumn{7}{|c|}{ QR to $F R$} \\
\hline Total & 0 & 2 & 5 & 6 & 4 & 2 \\
\hline B2B & 0 & 1 & 5 & 1 & 0 & 2 \\
\hline $\mathrm{B} 2 \mathrm{C}$ & 0 & 1 & 0 & 5 & 4 & 0 \\
\hline
\end{tabular}

In the study by Carlshamre et al., three of five case companies viewed value related (ICOST or CVALUE) interdependency types as the most common [7]. In the remaining two cases, functionality related (i.e., AND or REQUIRES) types were most common. Our results show a mix of value and functionality types as the most common ones (with the exceptions of Company E, I, and J).

The difference between the studies may be explained by the focus, i.e. we focused solely on interdependencies related to QR, while in Carlshamre et al. the focus was on requirements in general [7]. Moreover, we looked into interdependencies for the entire product, while Carlshamre et al. focused on dependencies among 20 selected requirements [7]. In addition, we have 11 case companies, compared to five in Carlshamre et al [7]. However, our results of a mix of value and functionality related types as the most common ones are inline with a study by Berntsson Svensson et al. [6].

The softgoal interdependency graph (SIG) [9], [10] is used to show interdependencies among QR. The interdependency types used in the SIG are limited to $A N D$, and $O R$, which is not inline with the findings in our study, as we found that seven different interdependency types were present in the companies. Furthermore, the types $A N D$, and $O R$, where viewed among the least common interdependency types among $\mathrm{QR}$ as well as between $\mathrm{QR}$ and FR.

RQ2.1: What interdependencies are deemed most important, and how does this compare to previous studies? According to the interviewees, the most important interdependency type to identify among $\mathrm{QR}$ was $R E$ QUIRES; however, B2B and $\mathrm{B} 2 \mathrm{C}$ were not in agreement.

B2B companies considered REQUIRES and ICOST as the most important, while REQUIRES and CVALUE were prioritized by $\mathrm{B} 2 \mathrm{C}$. One interviewee explained that ICOST is important for B2B because "the cost is lower for $R_{2}$ if $R_{1}$ is implemented, then we get a higher return of investment for that requirement". Only two interviewees identified $O R$, and only one identified AND as the most important interdependency types.

Interestingly, in identifying the most important interdependency type between QR and FR, the total result was identical to interdependency types among $Q R$. On closer examination the result between $\mathrm{B} 2 \mathrm{~B}$ and $\mathrm{B} 2 \mathrm{C}$ varies.

B2B prioritized TEMPORAL, but also uniquely identified TEMPORAL and ICOST. According to one interviewee, TEMPORAL is the most important type "due to high cost and delay in the schedule if this does not work". One explanation of why ICOST was identified by industry products is, according to one interviewee, "due to getting a lower cost when designing software from "cheap" hardware components".

B2C prioritized REQUIRES, but also uniquely identified CVALUE. One interviewee explained that REQUIRES is the most important interdependency type because "functionality first, then the quality aspect of the functionality is relevant".

Surprisingly, AND was not viewed as the most important interdependency type between $Q R$ and FR by any of the interviewees. The low result for $A N D$, and $O R$ interdependency types as the most common and important ones raises the question how useful the SIG [9], [10] is in an industrial context.

It is not surprising that $\mathrm{B} 2 \mathrm{~B}$ and $\mathrm{B} 2 \mathrm{C}$ have different views on interdependency priority. According to Carlshamre et al., value-related interdependencies are subjective; it may be difficult to state whether the cost exceeds the value for the customer [7].

Surprisingly, both among QR, and between $Q R$ and FR, REQUIRES is considered the most important to identify looking at the summation of all interviewees. This result is not inline with Carlshamre et al., which found that ICOST and CVALUE were the most important types of interdependencies in market-driven developing companies, while REQUIRES was considered the most important in bespoke (also known as contract development [29]) developing companies [7]. One interviewee explained that REQUIRES is considered the most important interdependency to identify because "this is the easiest type to miss, and therefore the most important to identify".

RQ2.2: To what extent are interdependencies elicited, analyzed, and documented? The interviews indicated a rather good agreement between the PM views and the views of the PL regarding whether or not interdependencies are elicited, analyzed and documented in the case organizations, as can be seen in Table 5 .

In two (E, I) of the six B2B companies the PM and PL agree that the case organization does not carry out elicitation, analysis or documentation of interdependencies among QR, while the other four B2B companies (A, B, H, $J$ ) indicate activities where interdependencies are managed, some at late stages of design (A, B) and some during workshops and customer meetings $(\mathrm{H}, \mathrm{J})$. 
TABLE 5

INTERDEPENDENCY MANAGEMENT

\begin{tabular}{|c|c|c|c|c|c|c|c|}
\hline & \multicolumn{2}{|c|}{ Elicited } & \multicolumn{2}{|c|}{ Analyzed } & \multicolumn{2}{|c|}{ Documented } & \multirow{2}{*}{$\begin{array}{l}\text { Impact on product devel- } \\
\text { opment }\end{array}$} \\
\hline & PM & PL & PM & PL & PM & PL & \\
\hline \multicolumn{8}{|c|}{ Business-to-business companies (B2B) } \\
\hline A & $\begin{array}{l}\text { Only during } \\
\text { change request }\end{array}$ & No & $\begin{array}{l}\text { In impact } \\
\text { analysis }\end{array}$ & No & $\begin{array}{l}\text { In the impact } \\
\text { analysis }\end{array}$ & No & $\begin{array}{l}\text { Add features and FR affects } \\
\text { the performance }\end{array}$ \\
\hline B & $\begin{array}{l}\text { During imple- } \\
\text { mentation } \\
\text { proposal }\end{array}$ & $\begin{array}{l}\text { During the } \\
\text { design phase }\end{array}$ & No & $\begin{array}{l}\text { During the } \\
\text { design phase }\end{array}$ & $\begin{array}{l}\text { In the imple- } \\
\text { mentation } \\
\text { proposal }\end{array}$ & $\begin{array}{l}\text { Written down as } \\
\text { bundled require- } \\
\text { ments in the } \\
\text { design }\end{array}$ & $\begin{array}{l}\text { Delayed or removed re- } \\
\text { quirements }\end{array}$ \\
\hline $\mathrm{E}$ & No & No & No & No & No & No & An incomplete product \\
\hline $\mathrm{H}$ & $\begin{array}{l}\text { Brainstorming, } \\
\text { and in work- } \\
\text { shops and } \\
\text { meetings }\end{array}$ & $\begin{array}{l}\text { During } \\
\text { workshops } \\
\text { and meetings }\end{array}$ & $\begin{array}{l}\text { Both external } \\
\text { (customer) } \\
\text { and internal } \\
\text { (workshops) }\end{array}$ & $\begin{array}{l}\text { Continuously } \\
\text { during work- } \\
\text { shops and } \\
\text { meetings }\end{array}$ & $\begin{array}{l}\text { In different } \\
\text { documents }\end{array}$ & $\begin{array}{l}\text { In Excel, Power- } \\
\text { Point, sketches, } \\
\text { and by using } \\
\text { UML }\end{array}$ & Order of implementation \\
\hline I & No & No & No & No & No & No & The design of the system \\
\hline $\mathrm{J}$ & $\begin{array}{l}\text { By each engi- } \\
\text { neer and during } \\
\text { workshops }\end{array}$ & $\begin{array}{l}\text { No, due to } \\
\text { cost }\end{array}$ & $\begin{array}{l}\text { First individ- } \\
\text { ually, then in } \\
\text { a workshop }\end{array}$ & $\begin{array}{l}\text { Using historical } \\
\text { data and work- } \\
\text { shops }\end{array}$ & $\begin{array}{l}\text { In the require- } \\
\text { ments specifica- } \\
\text { tion, for tracea- } \\
\text { bility }\end{array}$ & $\begin{array}{l}\text { In the require- } \\
\text { ments specifica- } \\
\text { tion, for traceabil- } \\
\text { ity }\end{array}$ & $\begin{array}{l}\text { Order of implementation of } \\
\text { other QR }\end{array}$ \\
\hline \multicolumn{8}{|c|}{ Business-to-consumer companies (B2C) } \\
\hline $\mathrm{C}$ & No & No & No & No & No & No & $\begin{array}{l}\text { Order of implementation, } \\
\text { planning and the quality level }\end{array}$ \\
\hline $\mathrm{D}$ & No & No & No & No & No & No & $\begin{array}{l}\text { The maintainability of the } \\
\text { system and the planning }\end{array}$ \\
\hline $\mathrm{F}$ & No & $\begin{array}{l}\text { During } \\
\text { workshops }\end{array}$ & No & $\begin{array}{l}\text { During work- } \\
\text { shops by group- } \\
\text { ing require- } \\
\text { ments }\end{array}$ & No & $\begin{array}{l}\text { Sometimes, it is } \\
\text { optional. Docu- } \\
\text { mented in a large } \\
\text { html document }\end{array}$ & Order of implementation \\
\hline $\mathrm{G}$ & $\begin{array}{l}\text { During re- } \\
\text { quirements } \\
\text { breakdown }\end{array}$ & No & $\begin{array}{l}\text { When break- } \\
\text { ing down } \\
\text { requirements }\end{array}$ & Not for QR & $\begin{array}{l}\text { In the require- } \\
\text { ments specifica- } \\
\text { tion }\end{array}$ & No & Limits possible options \\
\hline $\mathrm{K}$ & No & $\begin{array}{l}\text { By the archi- } \\
\text { tect }\end{array}$ & $\begin{array}{l}\text { As a conse- } \\
\text { quence of } \\
\text { prioritization }\end{array}$ & $\begin{array}{l}\text { Of the architec- } \\
\text { ture }\end{array}$ & $\begin{array}{l}\text { By the design } \\
\text { team }\end{array}$ & In the architecture & $\begin{array}{l}\text { Order of implementation and } \\
\text { the quality level }\end{array}$ \\
\hline
\end{tabular}

For B2C companies it is only one out of five companies for which PM and PL agree that the case organization manage interdependencies to any large extent $(\mathrm{K})$, while a few indications of limited activities can be found at two other B2C organizations (F, G).

In total for as many as seven out of 11 case organizations, either both or one of PM and PL indicate low extent of interdependency management (A, E, J, C, D, F, G). One reason for this may be that dealing with interdependencies is a complex task and the number of potential dependencies may be very large, resulting in an ad hoc approach to interdependency management where only a limited set of critical interdependencies are dealt with. This hypothesis is in line with the results from the study by Karlsson et al. [26]. Other explanations were discovered during the interviews. Several interviewees stated that $\mathrm{QR}$ are assumed and, therefore, not actively looked for. One interviewee explained that dependencies related to QR are not handled "because we have a focus on functionality. We fulfill what our customers' want and do not reflect over $Q R^{\prime \prime}$.

Concerning the impact of interdependencies on prod-

uct development, the interviewees stress several examples, as reported in Table 5. As many as five of the case organizations $(\mathrm{H}, \mathrm{J}, \mathrm{C}, \mathrm{F}, \mathrm{K})$ report that the order of implementation is affected by interdependencies, and company $B$ indicates that delays or exclusions of requirements may be the result of $\mathrm{QR}$ interdependencies, which also affects what is implemented. Furthermore, four of the companies (A, E, C, D) stated that the quality of the product is affected, e.g. performance and maintainability. Also the design of the system may be affected (I, G) in terms of limiting possible options.

\subsection{Cost Estimations (RQ3)}

Looking at how cost estimations are performed for QR the immediate response from all companies, and roles, was that no distinction was made between quality and functional requirements. Looking at Table 6, all of the companies stated that expert opinion was the predominant method used for estimation, which is inline with the results from Molokken and Jorgensen [33]. Some companies stated that historical data and previous experience of similar projects was used in an ad-hoc manner (E, J, F), 
mainly as an effect of the fact that the experts had done estimations before. Table 6 summarizes the perceived accuracy of estimations at the companies, for example, Company A the PM answered that in the worst case the estimates were off by $100 \%$, but the normal case was about $25 \%$ off, and at best it was accurate. In general, PM estimates the cost to be slightly higher than PL in the normal case (p-value 0.040 ).

The spread between the companies regarding accuracy is quite large, from e.g. Company $\mathrm{C}$ where worst case is $80 \%$ off and best is $0 \%$ off, to Company $\mathrm{B}$, which ranges from $300 \%$ to $50 \%$ at best.

TABLE 6

Cost Estimation Accuracy and Method

\begin{tabular}{|c|c|c|c|c|c|c|}
\hline \multirow[t]{2}{*}{ 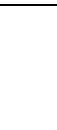 } & \multirow[t]{2}{*}{ Role } & \multicolumn{3}{|c|}{$\begin{array}{l}\text { Accuracy (percentage of } \\
\text { wrong estimates) }\end{array}$} & \multirow{2}{*}{\multicolumn{2}{|c|}{ Type of estimation }} \\
\hline & & Worst & Normal & Best & & \\
\hline \multicolumn{7}{|c|}{ Business-to-business companies (B2B) } \\
\hline \multirow[t]{2}{*}{ A } & PM & $100 \%$ & $25 \%$ & $0 \%$ & \multirow{2}{*}{\multicolumn{2}{|c|}{$\begin{array}{l}\text { Experts using implementa- } \\
\text { tion proposal }\end{array}$}} \\
\hline & PL & NA & NA & NA & & \\
\hline \multirow[t]{2}{*}{ B } & PM & $300 \%$ & $80 \%$ & $50 \%$ & \multirow{2}{*}{\multicolumn{2}{|c|}{ Expert estimations }} \\
\hline & PL & $200 \%$ & $25 \%$ & $10 \%$ & & \\
\hline \multirow[t]{2}{*}{$\mathrm{E}$} & PM & $75 \%$ & $50 \%$ & $25 \%$ & \multirow{2}{*}{\multicolumn{2}{|c|}{$\begin{array}{l}\text { Expert estimations and } \\
\text { previous projects }\end{array}$}} \\
\hline & PL & $70 \%$ & $30 \%$ & $0 \%$ & & \\
\hline \multirow[t]{2}{*}{$\mathrm{H}$} & PM & $100 \%$ & $40 \%$ & $0 \%$ & \multirow{2}{*}{\multicolumn{2}{|c|}{$\begin{array}{l}\text { Previous experience and } \\
\text { gut feeling }\end{array}$}} \\
\hline & PL & $80 \%$ & $50 \%$ & $20 \%$ & & \\
\hline \multirow[t]{2}{*}{ I } & PM & $200 \%$ & $50 \%$ & $25 \%$ & \multirow{2}{*}{\multicolumn{2}{|c|}{$\begin{array}{l}\text { Expert estimations using } \\
\text { related information }\end{array}$}} \\
\hline & PL & $75 \%$ & $0 \%$ & $0 \%$ & & \\
\hline \multirow[t]{2}{*}{$\mathrm{J}$} & PM & $40 \%$ & $20 \%$ & $20 \%$ & \multirow{2}{*}{\multicolumn{2}{|c|}{ Historical data }} \\
\hline & PL & $40 \%$ & $20 \%$ & $20 \%$ & & \\
\hline \multicolumn{7}{|c|}{ Business-to-consumer companies (B2C) } \\
\hline \multirow[t]{2}{*}{$\mathrm{C}$} & PM & NA & NA & NA & \multirow{2}{*}{\multicolumn{2}{|c|}{ Expert estimations }} \\
\hline & PL & $80 \%$ & $25 \%$ & $0 \%$ & & \\
\hline \multirow[t]{2}{*}{$\mathrm{D}$} & PM & $200 \%$ & $40 \%$ & $10 \%$ & \multirow{2}{*}{\multicolumn{2}{|c|}{ Expert estimations }} \\
\hline & PL & $300 \%$ & $50 \%$ & $25 \%$ & & \\
\hline \multirow[t]{2}{*}{$\mathrm{F}$} & $\mathrm{PM}$ & NA & NA & NA & \multirow{2}{*}{\multicolumn{2}{|c|}{$\begin{array}{l}\text { Expert estimations, gut } \\
\text { feeling, historical data }\end{array}$}} \\
\hline & PL & $50 \%$ & $0 \%$ & $0 \%$ & & \\
\hline \multirow[t]{2}{*}{ G } & PM & NA & NA & NA & \multirow{2}{*}{\multicolumn{2}{|c|}{ NA }} \\
\hline & PL & NA & NA & NA & & \\
\hline \multirow[t]{2}{*}{ K } & PM & $80 \%$ & $70 \%$ & $60 \%$ & \multicolumn{2}{|c|}{ Expert estimations } \\
\hline & PL & $50 \%$ & $35 \%$ & $15 \%$ & & \\
\hline \multicolumn{7}{|c|}{$\begin{array}{c}\text { TABLE } 7 \\
\text { COST ESTIMATION ACCURACY AvERAGES PER GROUP }\end{array}$} \\
\hline \multicolumn{3}{|c|}{ Type } & Wor & & Normal & Best \\
\hline & $2 \mathrm{~B}$ & $\overline{\mathrm{AVG}}$ & & 15 & 35 & 14 \\
\hline & & MED & & 5 & 33 & 13 \\
\hline & $2 \mathrm{C}$ & AVG & & 5 & 31 & 14 \\
\hline & & MED & & 8 & 35 & 9 \\
\hline
\end{tabular}

Comparing B2B with $\mathrm{B} 2 \mathrm{C}$ we can see the average and median for each group in Table 7 . The values are calculated by splitting the difference between the roles in each company and excluding company $\mathrm{G}$ (in the cases where data is NA the available data is used). From the results we can see that the worst-case alternative is the largest divider between the groups (B2B: AVG 115, MED 95 and B2C: AVG 55, MED 58). That is, the B2B group in the worst case has much more inaccurate estimates than the B2C group. The difference between the groups is almost non-existent in relation to the normal or best scenario.

From the interviews one reason for this was that the B2B companies had much larger single development instances (projects), and a worst-case scenario in a large project would give a larger estimation inaccuracy than the worst case of a smaller (shorter) B2C project (no statistical significance is claimed).

The interviews revealed that one predominant problem in estimating QR was their propensity to impact larger parts of a system, and span over several (or almost all) FR. For example, realizing most features is influenced by (or influences) the QR of performance. This result is not inline with Molokken and Jorgensen who found the major reasons for inaccurate estimates of requirements are overoptimistic estimates and user changes or misunderstandings [33].

The complexity of QR demands deeper analysis and using the same amount of resources and methods to estimate QR can have detrimental effects. This is strongly related to the level of dismissal of QR late in projects, covered in the next section.

\subsection{Dismissal of Quality Requirements (RQ4)}

We asked the interviewees how often $Q R$, specified and selected for inclusion in a project, were subsequently dismissed from projects during development (see Table 8). In average, $19 \%$ of all QR are dismissed; meaning almost every fifth QR planned and included in a project is dismissed at some stage prior to release. This result is inline with Berntsson Svensson et al., which found that $22.5 \%$ of all QR are dismissed at some stage [6]. When comparing $\mathrm{B} 2 \mathrm{~B}$ and $\mathrm{B} 2 \mathrm{C}$, the least amount of dismissed $\mathrm{QR}$ is slightly higher for B2B (4.5\%) than for B2C (3\%). In worst-case (Most in Table 8); in average, $41 \%$ of all $\mathrm{QR}$ are dismissed for B2B, while $31 \%$ in B2C.

According to the interviewees, there are three main trends of which types of QR that are more representative of the ones being dismissed.

First, there is no difference between types of QR; instead, other factors decide which ones are dismissed. One factor is the FR, one interviewee explained that the FR decides which $Q R$ that are dismissed because all $Q R$ that are related to the dismissed FR are also removed. A second factor according to one interviewee is that "usually the $Q R$ that are most important for the customer are the hardest to understand, and $Q R$ we do not understand are dismissed".

Second, for B2C, performance requirements are more often dismissed due to the difficulties in proper estimation. Third, for B2B, QR that are not visible to the customer, such as maintainability and testability, are more often 
dismissed than other $\mathrm{QR}$.

Moreover, QR that are not considered important for B2B are more often dismissed, for example, usability is more removed than the prioritized performance, which is inline with the result in RQ1 (see Section 4.1). One interviewee explained, "usability is more often dismissed because the damage for our customers is not that great. It is easier to sell a product with bad usability than with bad performance".

TABLE 8

ESTIMATED DISMISSAL RATES OF QUALITY REQUIREMENTS

\begin{tabular}{|c|c|c|c|c|c|}
\hline & \multirow[t]{2}{*}{ Role } & \multicolumn{3}{|c|}{ Dismissal rate } & \multirow[t]{2}{*}{ Reason for dismiss rate } \\
\hline & & Least & Avg. & Most & \\
\hline \multicolumn{6}{|c|}{ Business-to-business companies (B2B) } \\
\hline \multirow[t]{2}{*}{ A } & PM & $10 \%$ & $15 \%$ & $20 \%$ & \multirow{2}{*}{$\begin{array}{l}\text { Poor cost estimation, } \\
\text { testing QR very late }\end{array}$} \\
\hline & PL & $0 \%$ & $50 \%$ & $90 \%$ & \\
\hline \multirow[t]{2}{*}{ B } & PM & $10 \%$ & $20 \%$ & $90 \%$ & \multirow{2}{*}{$\begin{array}{l}\text { Poor cost estimation, } \\
\text { lack of resources }\end{array}$} \\
\hline & PL & $1 \%$ & $5 \%$ & $20 \%$ & \\
\hline \multirow[t]{2}{*}{$\mathrm{E}$} & PM & $0 \%$ & $50 \%$ & $100 \%$ & \multirow{2}{*}{$\begin{array}{l}\text { Poor cost estimation, } \\
\text { lower priority than FR }\end{array}$} \\
\hline & PL & $10 \%$ & $25 \%$ & $50 \%$ & \\
\hline \multirow[t]{2}{*}{$\mathrm{H}$} & PM & $0 \%$ & $10 \%$ & $30 \%$ & \multirow[t]{2}{*}{ Lower priority than FR } \\
\hline & PL & NA & NA & NA & \\
\hline \multirow[t]{2}{*}{ I } & PM & $0 \%$ & $2 \%$ & $10 \%$ & \multirow{2}{*}{$\begin{array}{l}\text { Lack of resources, QR } \\
\text { not quantified }\end{array}$} \\
\hline & PL & $10 \%$ & $15 \%$ & $20 \%$ & \\
\hline \multirow[t]{2}{*}{$\mathrm{J}$} & PM & $<10 \%$ & $0 \%$ & $10 \%$ & \multirow[t]{2}{*}{ Poor cost estimation } \\
\hline & PL & $<10 \%$ & $<10 \%$ & $10 \%$ & \\
\hline \multicolumn{6}{|c|}{ Business-to-consumer companies (B2C) } \\
\hline \multirow[t]{2}{*}{$\mathrm{C}$} & PM & NA & NA & NA & \multirow{2}{*}{$\begin{array}{l}\text { Poor cost estimation, } \\
\text { lack of resources, lower } \\
\text { priority than FR }\end{array}$} \\
\hline & PL & NA & NA & NA & \\
\hline \multirow[t]{2}{*}{$\mathrm{D}$} & PM & $0 \%$ & $5 \%$ & $10 \%$ & \multirow{2}{*}{$\begin{array}{l}\text { Issues we cannot affect, } \\
\text { e.g. network capacity }\end{array}$} \\
\hline & PL & $0 \%$ & $10 \%$ & $20 \%$ & \\
\hline \multirow[t]{2}{*}{$\mathrm{F}$} & PM & NA & NA & NA & \multirow[t]{2}{*}{ Hardware constraints } \\
\hline & PL & $0 \%$ & $10 \%$ & $20 \%$ & \\
\hline \multirow[t]{2}{*}{ G } & PM & $0 \%$ & $10 \%$ & $20 \%$ & \multirow{2}{*}{$\begin{array}{l}\text { Lack of resources, new } \\
\text { product development }\end{array}$} \\
\hline & PL & $0 \%$ & $30 \%$ & $50 \%$ & \\
\hline \multirow[t]{2}{*}{ K } & PM & $20 \%$ & $60 \%$ & $90 \%$ & \multirow{2}{*}{$\begin{array}{l}\text { Poor cost estimation, } \\
\text { lower priority than FR }\end{array}$} \\
\hline & PL & $2 \%$ & $3 \%$ & $5 \%$ & \\
\hline
\end{tabular}
QR:

The result reveals three main reasons for dismissal of

(1) Poor cost estimations

(2) Lack of resources

(3) QR have lower priority than FR.

There was no major difference between B2B and B2C with regards to why $\mathrm{QR}$ are dismissed from projects.

Poor cost estimations is related to the difficulties to estimate the cost of QR that have a global impact on the system, which is inline with the result in RQ3 (Section 4.3). The difficulties of estimating the cost of $Q R$ are related to the complexity of $\mathrm{QR}$, lack of knowledge, and understanding of how to manage $Q R$ in practice.
Lack of resources is related to prioritization of what is important to implement. One interviewee explained that their resources had more important tasks to do, and there is a lack of resources to optimize $Q R$, therefore it is easier to dismiss them.

Several interviewees frequently described that $Q R$ have lower priority, and that they do not spend much time on managing QR. Some of the interviewees explained that QR are seen as base requirements and therefore not considered. One interviewee explained, "in general it is easier to dismiss $Q R$ than FR". However, this focus has implications on the system, as explained by one interviewee, "in most situations, $Q R$ are down prioritized by $F R$ due to lack of knowledge of how important a system's quality is. By lowering the quality level, the value of the system decreases".

RQ4.1: If QR are dismissed, is any consequence analysis performed pre- or post dismissal? In $82 \%$ of the companies it was revealed that there is a lack of communication between PM and PL. PM stated that there is a consequence analysis, while the PL stated that no consequence analysis is preformed.

In $55 \%$ of those companies (a mix of B2B and B2C), PM stated that a consequence analysis is only conducted if the customers are directly affected. The consequence analysis may include new prioritization of all requirements and new cost estimations, as explained by one interviewee, "if we have promised a certain quality, then we have to increase the cost for this project and accept a lower return of investment".

Another consequence, as explained by one PM, is to "first ask the customer if this is OK. If not, we talk to the developers to find out the reason why this cannot be done. Finally, we decide if we have to add or remove other requirements".

Surprisingly, none of the PL shared the view of the PM. All PL claimed that nothing happens when QR were dismissed from the projects. One explanation, which was qualified by one PL, is that "we do not have time to reanalyze the consequence of $Q R$, other things are more important".

Another explanation according to another PL, "if we remove $Q R$ we can deliver on time". Only in two companies (Company J and K) was there an agreement between PM and PL. In Company J, a consequence analysis is performed in terms of new cost estimations, while in Company $\mathrm{K}$ no analysis is conducted.

A central issue here seems to be the difficulty to properly quantify as well as estimate the cost of implementing a $Q R$, but more importantly the value of a $Q R$. This is inline with a study by Lehtola and Kauppinen, which found that communication problems were a difficulty for understanding the importance of a requirement [30]. This might indicate a lack of estimation models / techniques for $Q R$.

The result from RQ3 (Section 4.3) shows that the same cost estimation strategy is used for QR as for FR. Maybe $\mathrm{QR}$ needs to be estimated with a different strategy. The complexity is of course that a QR often implies a quality aspect of a system/product. Such a quality aspect is often not realized as a feature, but rather implies that all development be in line and adhering to the quality aspect. For 
example, performance is not dictated by one thing, but often by how the system is realized overall, including architectural considerations impacting the whole.

RQ4.2: Are QR specified in a measurable (quantifiable) manner? Looking at Table 9 , in $64 \%$ of all companies the view of how often $Q R$ are quantified differed between PM and PL. Interestingly, in $82 \%$ of all companies, the PL claimed that $\mathrm{QR}$ were quantified sometimes, while in $67 \%$ of these cases the PM views differed, stating always or never.

TABLE 9

QUANTIFICATION OF QUALITY REQUIREMENTS

\begin{tabular}{|c|c|c|}
\hline Company & Role & Answer \\
\hline \multicolumn{3}{|c|}{ Business-to-business companies (B2B) } \\
\hline \multirow[t]{2}{*}{ A } & PM & Always \\
\hline & PL & Sometimes \\
\hline \multirow[t]{2}{*}{ B } & $\mathrm{PM}$ & Never \\
\hline & PL & Sometimes \\
\hline \multirow[t]{2}{*}{$\mathrm{E}$} & PM & Always \\
\hline & PL & Sometimes \\
\hline \multirow[t]{2}{*}{$\mathrm{H}$} & PM & Sometimes \\
\hline & PL & Sometimes \\
\hline \multirow[t]{2}{*}{ I } & PM & Always \\
\hline & PL & Sometimes \\
\hline \multirow[t]{2}{*}{$\mathrm{J}$} & $\mathrm{PM}$ & Never \\
\hline & PL & Always \\
\hline \multicolumn{3}{|c|}{ Business-to-consumer companies (B2C) } \\
\hline \multirow[t]{2}{*}{$\mathrm{C}$} & PM & Always \\
\hline & PL & Always \\
\hline \multirow[t]{2}{*}{$\mathrm{D}$} & PM & Sometimes \\
\hline & PL & Sometimes \\
\hline \multirow[t]{2}{*}{$\mathrm{F}$} & PM & Always \\
\hline & PL & Sometimes \\
\hline \multirow[t]{2}{*}{ G } & PM & Sometimes \\
\hline & PL & Sometimes \\
\hline \multirow[t]{2}{*}{ K } & PM & Always \\
\hline & PL & Sometimes \\
\hline
\end{tabular}

For B2B, PM and PL had different views in $83 \%$ of the companies, while only $40 \%$ of B2C had different views. In total, $36 \%$ of all interviewees claimed that $\mathrm{QR}$ are always quantified. However, when examining the result for B2B and $\mathrm{B} 2 \mathrm{C}$ separately, there is a small difference.

For B2B, 33\% of the interviewees stated that QR are always quantified, while $40 \%$ in B2C. Only in 36\% of the companies (Company C, D, G, and H) an agreement between PM and PL could be observed. Interestingly, three of these companies $(\mathrm{C}, \mathrm{D}$, and $\mathrm{G})$ are $\mathrm{B} 2 \mathrm{C}$.

The disagreement may be an indication of communication problems between the PM and PL. Communication problems were also identified as a challenge in marketdriven RE by several studies [6], [13], [14], and [26].
It is surprising to note that both interviewees stating that $\mathrm{QR}$ are never quantified represent $\mathrm{B} 2 \mathrm{~B}$. This is related to identified challenges with regards to $Q R$ and the perceived difficulties in achieving testable QR [6], which may explain why QR are not always quantified. Another possible explanation may be that some $\mathrm{QR}$ are more difficult to quantify than others, e.g. usability requirements are more difficult to quantify than performance requirements. Kamsties et al. found that the specification of usability requirements is a challenge [25]. Furthermore, another explanation may be that not all $\mathrm{QR}$ are suitable to be quantified, e.g. due to the nature of security requirements, many of them may not be suitable for quantification. In addition, as found in [34], many QR refers to different standards where the quantification part may be hidden.

In a study by Olsson et al., about half of the QR were found to be quantified which seems to confirm the findings [34]. However, one interesting observation that cannot be directly confirmed is the level of disagreement between PM and PL. It should be noted that each PM and PL pair worked for the same company, and moreover with the same project.

\section{Conclusions}

In conclusion, this paper presents the results of an empirical study that examines $\mathrm{QR}$ in practice in eleven software companies. Data is collected from eleven PMs and eleven PLs at the companies, thus constituting 22 in-depth interviews in total.

In relation to RQ1, which $Q R$ are considered most important, the findings reveal that: (1) in general and especially for B2C, usability is deemed the most important $\mathrm{QR}$, and (2) for B2B, safety is considered the most important aspect. The importance of identifying the needs of a particular company type before dealing with improvements of how to handle QR can of course be discussed.

One solution could be to develop ways (models, tools, techniques) to handle all types of QR for all types of industry. However, the rather immature level of QR handling in industry, in spite of research efforts, may indicate that a blanket solution might not be the best way to go. Rather aimed approaches to e.g. figuring out how companies can handle the most important (to them) QR could be an alternative.

What we can say is that not all QR are equally important for all company types. This insight of difference in priorities is important for e.g. researchers, as it enables focus on certain quality aspects in research depending on company type. These findings complement the findings of [5], [6] [23], which, in part, confirm this; however, it contradicts [31].

The findings for RQ2, interdependencies, show that: (1) REQUIRES and CVALUE are considered as the most common and important interdependency types to identify, (2) while B2B viewed REQUIRES as the most common and important one, B2C considered CAVLUE, and (3) $A N D$, and $O R$ were considered the least common and least important interdependency types. This can be seen 
as rather interesting as most software engineering research on $\mathrm{QR}$ is performed on realization/implementation level where $A N D$ and $O R$ are the dominant perspectives investigated (e.g. architectures, implementation order etc.) [8], [10], [27]. Fewer studies are devoted to for example the value aspects which are conveniently pushed out of the scope of engineering [7].

Interdependencies can have a critical impact on product development in terms of e.g. planning, design and quality. Despite the importance to identify interdependencies, few of the companies actually manage to a large extent to effectively elicit, analyze and document interdependencies. The identification of dependencies is a complex task and the potential number of dependencies may be very large. Therefore, the understanding of which interdependency types are considered most important may give an indication to practitioners of which to start to identify.

For researchers, the knowledge of which interdependency types that exists, are the most common and important ones, provides a focus of what to include in potential new models / techniques for identifying, specifying and managing dependencies. These findings complement the findings of [6], [26], who to part confirms this; however, it contradicts [7], [9], [10]. The impact interdependencies of $\mathrm{QR}$ have on product development are uniquely reported by this paper.

In relation to $\mathrm{RQ3}$, cost estimation of $\mathrm{QR}$, the findings show that:

(1) There is no distinction between FR and QR during cost estimation

(2) Expert opinion is the predominant method for estimation

(3) In worst case, B2B has much more inaccurate estimates than $\mathrm{B} 2 \mathrm{C}$.

Difficulties of estimating QR may be related to their large impact on the entire system and span over all most all FR, which makes it hard to estimate the cost. However, inaccurate estimates of QR have major effects on the entire system. Therefore, it is important for practitioners to understand that estimates of QR demand a deeper analysis, and using the same resources and methods for $Q R$ and FR may not provide accurate estimates.

For researchers, the inaccurate estimates of $\mathrm{QR}$ enable a focus on models / techniques with focus on QR for cost estimation. These findings complement the findings of [25] and [33], who to part confirms this; however, it contradicts [33] with regards to reasons for inaccurate estimates. Furthermore, this paper uniquely reports the perceived inaccuracy of QR estimates, and reasons for inaccurate estimates of QR.

The findings for RQ4, dismissal of $\mathrm{QR}$, reveal that:

(1) Close to 1 out of 5 of all QR are dismissed from the projects at some stage during development, with little or no consequence analysis performed

(2) For B2C, performance requirements are more often dismissed due to the difficulties in proper estimation, while for B2B, QR that are not considered important, for example, usability is more often dismissed than performance requirements

(3) Poor cost estimation and the fact that QR have lower priority than FR are the main reason for dismissal.

The importance of QR needs to be acknowledged by practitioners, not only in theory, but also in practice. Dismissal of QR may solve a short-term problem; however, in the long-term, which the results reveal, the value of the system and the competitive advantage may decrease. These findings complement the findings of [6], [13], [26]. Some QR are easier to specify and test than others, for example, performance requirements are easy to specify and test; however, they affect a large part of FR that may make them difficult to keep in the project. Other $Q R$, for example, usability requirements are more difficult to specify and test. To lower the dismiss rate of QR, by improving the specification and quantification of the more difficult ones, it may be easier to keep them in the project instead of dismissing when running out of time.

In general, the results indicate that there might be a difference in relation to type of company (B2B or B2C). Furthermore, there seems to be a bespoke development mindset where the immediate project gets a higher priority than the long-term evolution of the product. Having an extra function is considered more valuable than higher quality. This contradicts the initial view (RQ1) where QR were labeled as critical. In addition, there seem to be difficulties in committing to $\mathrm{QR}$, especially when there is pressure to deliver the product. However, the main problem is that $Q R$ are not taken into consideration during product planning and thus not included as hard requirements in the projects, making the realization of $\mathrm{QR}$ a reactive rather than proactive effort. Product management may thus not be able to plan and rely on $\mathrm{QR}$ to achieve competitive advantages.

\section{ACKNOWLEDGMENT}

This work was partly funded by VINNOVA (the Swedish Agency for Innovation Systems) within the MARS project and by the Industrial Excellence Center EASE - Embedded Applications Software Engineering, (http://ease.cs.lth.se). Furthermore, we would like to thank all of the participants and their companies who have helped in making the data collection possible for this research.

\section{REFERENCES}

[1] H. Al-Kilidar, K. Cox and B. Kitchenham, "The use and usefulness of the ISO/IEC 9126 quality standard," Proc. Int. Symp. on Empirical Software Engineering, pp. 126-132, 2005.

[2] D. Alwis, V. Hlupic and G. Fitzgerald, "Intellectual capital factors that impact of value creation," Proc. $25^{\text {th }}$ Int. Conf. on Information Technology Interfaces, pp. 411-416, 2003.

[3] A. Aurum and C. Wohlin, Engineering and Managing Software Requirements (eds.), New York: Springer, 2005.

[4] S. Barney, A. Aurum and C. Wohlin, "A product management challenge: Creating software product value through requirements selection," J. of Systems Architecture, vol. 54, no. 6, pp. 576-593, Jun. 2008. 
[5] R. Berntsson Svensson and A. Aurum, "Successful software project and products: An empirical investigation," Proc. Fifth Int. Symp. On Empirical Software Engineering, pp. 144-153, 2006.

[6] R. Berntsson Svensson, T. Gorschek and B. Regnell, “Quality Requirements in Practice: An interview Study in Requirements Engineering for Embedded Systems," Requirements Engineering: Foundation for Software Quality, M. Glinz and P. Heymans, eds., LNCS 5512, Heidelberg: Springer, pp. 218-232, 2009.

[7] P. Carlshamre, K. Sandahl, M. Lindvall, B. Regnell and J. Natt och Dag, "An Industrial Survey of Requirements Interdependencies in Software Product Release Planning," Proc. Fifth IEEE Int. Symp. On Requirements Engineering, pp. 84-91, 2001.

[8] L. Chung, B.A. Nixon and E. Yu, "Using Non-Functional Requirements to Systematically Support Change," Proc. Second IEEE Int. Conf. on Requirements Engineering, pp. 132-139, 1995.

[9] L. Chung, B.A. Nixon, E. Yu and J. Mylopoulos, Non-Functional Requirements in Software Engineering, Kluwer Academic Publisher, 2000.

[10] J. Cleland-Huang, R. Settimi, O. BenKhadra, E. Berezhanskaya and S. Christina, "Goal-Centric Traceability for Managing Non-Functional Requirements," Proc. 27 $7^{\text {th }}$ Int. Conf. on Software Engineering, pp. 362-371, 2005.

[11] L.M. Cysneiros and J.C.S.P. Leite, “Nonfunctional Requirements: From Elicitation to Conceptual Models," IEEE Trans. on Software Engineering, vol. 30, no. 5, pp. 328-349, May 2004.

[12] C. Ebert, "Putting requirements into praxis: dealing with non-functional requirements," Information and Software Technology, vol. 40, no. 3, pp. 175-185, Jun. 1998.

[13] S. Fricker, T. Gorschek and M. Glintz, "Goal-Oriented Requirements Communication in New Product Development," Second Int. Workshop on Software Product Management, 2008.

[14] S. Fricker, T. Gorschek and P. Myllyperkiö, "Handshaking between Software Projects and Stakeholders Using Implementation Proposals," Requirements Engineering: Foundation for Software Quality, P. Sawyer, B. Peach and P. Heymans, eds., LNCS 4542, Heidelberg: Springer, pp. 144159, 2007.

[15] T. Gorschek and A. Davis, "Requirements Engineering: In Search of the Dependent Variable," Information and Software Technology, vol. 50, no. 12, pp. 67-75, Jan. 2008.

[16] T. Gorschek, P. Garre, S. Larsson and C. Wohlin, "Industry Evaluation of the Requirements Abstraction Model," Requirements Engineering Journal, vol. 12, no. 3, pp. 163-190, Jul. 2007.

[17] T. Gorschek and C. Wohlin, "Identification of Improvement Issues Using a Lightweight Triangulation Approach," Proc. European Software Process Improvement Conference, pp. VI.1-VI.14, 2003.

[18] T. Gorschek and C. Wohlin, "Requirements Abstraction Model," Requirements Engineering Journal, vol. 11, no. 1, pp. 79-101, Mar. 2006.

[19] S. Grimstad, M. Jorgensen and K. Molokken-Ostvold, "Software effort estimation terminology: The tower of Babel", Information and Software Technology, vol. 48, no. 4 pp. 302-310, Apr. 2006.

[20] M. Ivarsson and T. Gorscheck, "A Method for Evaluating Rigor and Industrial Relevance of Technology Evaluations," Empirical Software Engineering, in print, doi: 10.1007/s10664-010-9146-4.

[21] M. Ivarsson and T. Gorschek, "Technology Transfer Decision Support in Requirements Engineering Research: A Systematic Review of REj," Requirements Engineering Journal, vol. 14, no. 3, pp. 155-175, Jul. 2009.

[22] S. Jacobs, "Introducing Measurable Quality Requirements: A Case Study," Proc. Fourth IEEE Int. Symp. On Requirements Engineering, pp. 172-179, 1999.

[23] E. Johansson, A. Wesslen, L. Bratthall and M. Höst, "The importance of quality requirements in software platform development - a survey,"
Proc. 34 $4^{\text {th }}$ Annual Hawaii Int. Conf. on System Sciences, 2001.

[24] H-W. Jung, S-G. Kim and C-S. Chung, "Measuring software product quality: A survey of ISO/IEC 9126," IEEE Software, vol. 21, no. 5, pp. 88-92, Sep/Oct. 2004.

[25] E. Kamsties, K. Hörnmann and M. Schlich, "Requirements Engineering in Small and Medium Enterprises," Proc. Conf. on European Industrial Requirements Engineering, pp. 84-90, 1998.

[26] L. Karlsson, Å.G. Dahlstedt, B. Regnell, J. Natt och Dag and A. Persson, "Requirements engineering challenges in market-driven software development - An interview study with practitioners," Information and Software Technology, vol. 49, no. 6, pp. 588-604, Jun. 2007.

[27] R. Kazman, M. Barbacci, M. Klein, S.J. Carriere and S.G. Woods, "Experience with Performing Architecture Tradeoff Analysis," Proc. $9^{\text {th }}$ Int. Conf. On Software Engineering, pp. 54-63, 1999.

[28] S. Konrad and M. Gall, "Requirements engineering in the development of large-scale systems," Proc. $16^{\text {th }}$ IEEE Int. Requirement Engineering Conf., pp. 217-222, 2008.

[29] S. Lauesen, Software Requirements - Styles and Techniques, Great Brittan: Addison-Wesley, 2002.

[30] L. Lehtola and M. Kauppinen, "Suitability of Requirements Prioritization Methods for Market-Driven Software Product Development," Software Process: Improvement and Practice, vol. 11, no. 1, pp. 7-19, Jan. 2006.

[31] H.K.N. Leung, "Quality metrics for intranet applications," Information and Management, vol. 38, no. 3, pp. 137-152, Jan. 2001.

[32] M. Lubars, C. Potts and C. Richter, "A Review of the State of the Practice in Requirements Modeling," Proc. First IEEE Int. Symp. On Requirements Engineering, pp. 2-14, 1993.

[33] K. Molokken and M. Jorgensen, "A review of software surveys on software effort estimation," Proc. Int. Symp. On Empirical Software Engineering, pp. 223-230, 2003.

[34] T. Olsson, R. Berntsson Svensson and B. Regnell, "Non-functional requirements metrics in practice - an empirical document analysis," Workshop on Measuring Requirements for Project and Product Success, 2007.

[35] M.Q. Patton, Qualitative Research and Evaluation Methods, USA: Sage Publications, 2002.

[36] F. Pettersson, M. Ivarsson and T. Gorschek, "A Practitioner's Guide to Light Weight Software Process Assessment and Improvement Planning," Journal of Systems and Software, vol. 8, no. 16, pp. 972-995, Jun. 2008.

[37] C. Robson, Real World Research, Oxford: Blackwell, 2002.

[38] P. Runeson and M. Höst, "Guidelines for conducting and reporting case study research in software engineering," Empirical Software Engineering, vol. 14, no. 2, pp. 131-164, Apr. 2009.

[39] E. Turban, D. King, J.K. Lee and D. Viehland, Electronic Commerce: A Managerial Approach, Prentice Hall, 2006.

[40] C. Wohlin, P. Runeson, M. Höst, C. Ohlson, B. Regnell and A. Wesslén, Experimentation in Software Engineering: An Introduction, Boston: Kluwer Academic, 2000.

Richard Berntsson Svensson received the M.Sc. in software engineering degree from Blekinge Institute of Technology, Karlskrona, Sweden in 2006. He is a PhD student at Lund University's Department of Computer Science. He has published 15 papers in international journals, conferences, and workshop proceedings. His current research interests include quality requirements, marketdriven software development, and software product management.

Tony Gorschek is an associate professor of software engineering at Blekinge Institute of Technology (BTH). He has also worked as a consultant for over 10 years as well as the initiator of several startups. His research interests include requirements engineering, tech- 
nology and software product management, process assessment and improvement, quality assurance, and innovation. Most of the research is conducted in close collaboration and cooperation with industry partners such as $\mathrm{ABB}$ and Ericsson. Gorschek has a PhD (Tekn. Dr.) in software engineering from BTH. He's a member of the IEEE and the ACM. Contact him at tony.gorschek@bth.se or visit www.gorschek.com .

Björn Regnell is a professor of Software Engineering in Lund University's Department of Computer Science and Vice Dean of Research at the Faculty of Engineering, LTH. His research interests include market-driven software development, requirements engineering, software quality, software innovation, software product management, and empirical research methods. He has published more than 70 papers in these areas. He received his $\mathrm{PhD}$ in software engineering from Lund University, Sweden in 1999.

Richard Torkar is an associate professor at the School of Computing at Blekinge Institute of Technology. His focus is on quantitative research methods in the field of software engineering. He received his $\mathrm{PhD}$ in software engineering from Blekinge Institute of Technology, Sweden in 2006. He's a member of ACM and IEEE.

Ali Shahrokni received the M.Sc. degree from Chalmers University of Technology in Gothenburg, Sweden, year 2007. He is currently a Ph.D. student in the Software Engineering and Technology group at Chalmers University of Technology. He has published 5 papers in international conferences. His main interests are requirements engineering and verification and validation of quality of software. His early works were focused on human-computer interaction.

Robert Feldt (M'98) is an associate professor of software engineering at Chalmers University of Technology $(\mathrm{CHT})$ as well as at Blekinge Institute of Technology. He has also worked as an IT and Software consultant for more than 15 years. His research interests include software testing and verification and validation, automated software engineering, requirements engineering, user experience, and human-centered software engineering. Most of the research is conducted in close collaboration with industry partners such as Ericsson, RUAG Space and SAAB Systems. Feldt has a PhD (Tekn. Dr.) in software engineering from $\mathrm{CTH}$. 